\title{
The Productivity of Spring Wheat Depending on the Depth of Seeding in the Predkamye of the Republic of Tatarstan
}

\author{
Farit Shaikhutdinov, Igor Serzhanov*, Razil Garaev and Abdulsamad Valiev \\ Kazan State Agrarian University, 64, K. Marx str., 420015, Kazan, Russia
}

\begin{abstract}
The article describes the two-year experimental study of the effect of the seeding depth on the development of spring wheat plants, the nature of development of the root system and the stalk, which has an important effect on the yield and grain quality. It was found that on gray forest medium loamy soils of the region, the most effective seeding depth is $4-5 \mathrm{~cm}$.
\end{abstract}

\section{Introduction}

The amicability and completeness of seedlings depend on the depth of seeding, it affects the growth of the aboveground mass and development of the root system [1-3].

The seeding depth for spring wheat is of significant practical importance. It depends on the soil, moisture content, sowing time and seed quality [4-6].

On easily compacting soils, it is advisable to plant smaller seeds than on cultivated and structural soils [7-10].

\section{Methods}

The studied were conducted on the the territory of "Agrobiotechnopark" of Kazan State Agrarian University on light gray forest soils of a medium loamy mechanical composition. Full-fledged seeds of Ulyanovskaya 105 variety were sown. On a thoroughly prepared soil, the seeds were planted on plots with a total area of $40 \mathrm{~m}_{2}$ at a precisely set depth according to the adopted scheme (by 2, 3, 4, 5, 6, and $7 \mathrm{~cm}$ ) with soil rolling after sowing with heavy KKSH-3 rollers. Sowing was carried out with a Wintersteiger seed drill with appropriate adjustment and preliminary checking of the depth. For pre-sowing, mineral fertilizers were applied. The seeding rate was $6 \mathrm{mln}$. Sowing time was the first decade of May. The agricultural technology was generally accepted in the region.

\section{Results and discussion}

In 2019-2020, there were favorable meteorological conditions. In May-August of 2019, there were 1.5 times more precipitation, and in 2020 the precipitation was standard: GTK-1.36 and 1.13.

Observations of the growth and development of spring wheat have shown that depending on the seeding depth, the survival rate of plants and development phases change (Table 1).

Table 1. The effect of the seeding depth on the planting density (2019-2020)

\begin{tabular}{|c|c|c|c|c|}
\hline \multirow[t]{2}{*}{ Option } & \multirow{2}{*}{$\begin{array}{c}\text { Seeding } \\
\text { depth, cm }\end{array}$} & \multicolumn{2}{|c|}{ Plants per $1 \mathrm{~m}^{2}$} & \multirow{2}{*}{$\begin{array}{l}\text { Percentage of preserved } \\
\text { plants before harvesting of } \\
\text { the number of shoots }\end{array}$} \\
\hline & & $\begin{array}{l}\text { During the full } \\
\text { germination }\end{array}$ & $\begin{array}{c}\text { Before } \\
\text { haversting }\end{array}$ & \\
\hline 1 & 2 & 383 & 324 & 84,6 \\
\hline 2 & 3 & 396 & 363 & 89,1 \\
\hline 3 & 4 & 440 & 400 & 91,0 \\
\hline 4 & 5 & 443 & 390 & 89,8 \\
\hline 5 & 6 & 401 & 346 & 86,2 \\
\hline 6 & 7 & 372 & 304 & 81,9 \\
\hline
\end{tabular}

For spring wheat, the leaf surface area is a very

Table 1 shows that the highest plant density, both for seedlings and before harvesting, was observed in options 3 and $4-$ with a seeding depth of 4 and $5 \mathrm{~cm}$. The highest percentage of preserved plants was observed for the same options. important indicator, since the net productivity of photosynthesis, NPF, depends on the degree of its development (Table 2).

\footnotetext{
*Corresponding author: igor.serzhanov@mail.ru
} 
Table 2. Spring wheat leaf surface area (2019-2020)

\begin{tabular}{|c|c|c|c|c|c|c|c|}
\hline \multirow{3}{*}{ : } & \multirow{3}{*}{ 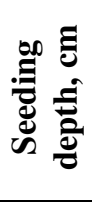 } & \multicolumn{6}{|c|}{ Phase } \\
\hline & & \multicolumn{2}{|c|}{ shooting } & \multicolumn{2}{|c|}{ earing } & \multicolumn{2}{|c|}{ Milk line } \\
\hline & & $\begin{array}{l}1 \text { plant, } \\
\mathrm{cm}^{2}\end{array}$ & $\begin{array}{c}\text { thousand } \mathrm{m}^{2} \\
\text { per } \\
1 \text { ha } \\
\end{array}$ & 1 plant, $\mathrm{cm}^{2}$ & $\begin{array}{c}\text { thousand } \\
\text { m² per }^{2} \\
1 \text { ha }\end{array}$ & 1 plant, $\mathrm{cm}^{2}$ & $\begin{array}{c}\text { thousand } \mathrm{m}^{2} \\
\text { per } \\
1 \text { ha } \\
\end{array}$ \\
\hline 1 & 2 & 61.2 & 23.4 & 73.7 & 28.2 & 24.6 & 8.0 \\
\hline 2 & 3 & 64.7 & 25.6 & 77.2 & 30.6 & 30.5 & 11.1 \\
\hline 3 & 4 & 70.3 & 30.9 & 79.4 & 34.9 & 34.9 & 14.0 \\
\hline 4 & 5 & 70.9 & 31.4 & 80.5 & 35.6 & 30.3 & 11.8 \\
\hline 5 & 6 & 65.1 & 26.1 & 75.6 & 30.3 & 26.7 & 9.2 \\
\hline 6 & 7 & 59.8 & 22.2 & 70.4 & 26.2 & 23.6 & 7.2 \\
\hline
\end{tabular}

Table 2 shows that the largest leaf surface in the booting phase was observed at a seeding depth of $4 \mathrm{~cm}$, and the smallest one - at a depth of $7 \mathrm{~cm}$. During the earing period, this it changed: the largest leaf surface of one plant was observed in plants with a seeding depth of 3 and $4 \mathrm{~cm}$. By this time, the growth of leaf surface in other options slightly decreased due to hot and dry weather.
The largest leaf area per unit area was in options 3 and $4-30.9$ and 31.4 thousand $\mathrm{m}^{2}$ per hectare. During the ripening period, the largest leaf area was observed at a seeding depth of $4 \mathrm{~cm}-14.0$ thousand $\mathrm{m}^{2}$ per hectare.

Our observations showed that the linear growth of plants, depending on the depth of planting of seeds, was not the same (Table 3).

Table 3. Linear plant growth dynamics, cm (2019-2020)

\begin{tabular}{|c|c|c|c|c|c|}
\hline \multirow{2}{*}{ Option } & Seeding depth, & \multicolumn{4}{|c|}{ Phase } \\
\cline { 3 - 6 } & cm & tillering & shooting & earing & ripeness \\
\hline 1 & 2 & 25.0 & 32.7 & 88.4 & 93.4 \\
2 & 3 & 25.1 & 31.6 & 100.2 & 103.5 \\
3 & 4 & 24.8 & 30.4 & 104.0 & 109.1 \\
4 & 5 & 24.7 & 30.0 & 102.5 & 105.6 \\
5 & 6 & 23.6 & 29.5 & 90.6 & 93.4 \\
6 & 7 & 23.0 & 28.3 & 90.0 & 92.1 \\
\hline
\end{tabular}

The data in Table 3 indicate that, before the tillering phase, the greatest growth in height was observed in options with a seeding depth of 2 and $3 \mathrm{~cm}-25.0$ and $25.1 \mathrm{~cm}$. In the shooting phase, this ratio remained the same $-32,7$ and $31.6 \mathrm{~cm}$. In the earing phase, the plants had the maximum height with a seeding of 4 and $5 \mathrm{~cm}$
$(104.0-102.5 \mathrm{~cm})$. Before harvesting, this indicator was highest in option 3 with a seeding depth of $4 \mathrm{~cm}$ and $109.1 \mathrm{~cm}$.

The seeding depth has a significant effect on the development of the root system of spring wheat (Table 4).

Table 4. The root system of spring wheat and its relation to the aboveground mass depending on the depth of seeding (2019-2020)

\begin{tabular}{|c|c|c|c|c|c|c|c|}
\hline \multirow{2}{*}{ อั } & \multirow{2}{*}{ 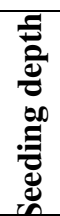 } & \multicolumn{2}{|c|}{$\begin{array}{c}\text { Root mass of one plant } \\
\text { in the tillering phase, } \\
\mathrm{g}\end{array}$} & \multicolumn{2}{|c|}{$\begin{array}{l}\text { Aboveground mass } \\
\text { of one plant, } g\end{array}$} & \multicolumn{2}{|c|}{ Ratio } \\
\hline & & raw & air dry & raw & air dry & $\begin{array}{c}\text { raw roots to raw } \\
\text { aboveground mass }\end{array}$ & $\begin{array}{l}\text { dry roots to dry } \\
\text { aboveground mass }\end{array}$ \\
\hline 1 & 2 & 0.22 & 0.08 & 0.80 & 0.18 & $1: 3.63$ & $1: 2.00$ \\
\hline 2 & 3 & 0.29 & 0.10 & 1.15 & 0.21 & $1: 3.96$ & $1: 2.10$ \\
\hline 3 & 4 & 0.36 & 0.12 & 1.45 & 0.26 & $1: 4.02$ & $1: 2.33$ \\
\hline 4 & 5 & 0.32 & 0.11 & 1.26 & 0.24 & $1: 3.94$ & $1: 2.18$ \\
\hline 5 & 6 & 0.25 & 0.09 & 0.9 & 0.19 & $1: 3.6$ & $1: 2.11$ \\
\hline 6 & 7 & 0.21 & 0.08 & 0.95 & 0.16 & $1: 3.57$ & $1: 1.88$ \\
\hline
\end{tabular}

The most powerful root system was in options with a seeding depth of 4 and $5 \mathrm{~cm}$, the mass of raw roots was 0.36 and 0.32 , respectively; the lowest this indicator was in plants with a seeding depth of 2 and $7 \mathrm{~cm}(0.22$ and $0.21 \mathrm{~g})$. The mass of air-dry roots changed with the same regularity.
The value of the aboveground mass of plants and the yield of grain depend on the root system. The seeding depth affects the ratio of the root system mass to the aboveground part of plants. Most of the raw aboveground mass per unit of raw root mass is at a seeding depth of $4 \mathrm{~cm}$ (1: 4.02). The smallest ratio of wet and dry elements was observed in the option where the root

*Corresponding author: igor.serzhanov@mail.ru 
system was developed worse - when the seeding depth was 2 and $7 \mathrm{~cm}(1: 3.63 ; 1: 2.00$ and $1: 3.57 ; 1: 1,88)$.
The yield of spring wheat also depends on the depth of seeding (Table 5).

Table 5. Spring wheat yield depending on the depth of seeding

\begin{tabular}{|c|c|c|c|c|c|c|}
\hline \multirow{2}{*}{ Option } & Seeding depth, & \multicolumn{3}{|c|}{ Yield, t/ha } & \multicolumn{2}{c|}{ Gain } \\
\cline { 3 - 7 } & $\mathrm{cm}$ & 2019 & 2020 & $\begin{array}{c}\text { Average for 2019- } \\
2020\end{array}$ & t/ha & \\
\hline 1 & 2 & 2.62 & 2.93 & 2.77 & 0.43 & 86.5 \\
2 & 3 & 2.75 & 3.19 & 2.97 & 0.23 & 92.8 \\
3 & 4 & 2.94 & 3.46 & 3.20 & - & 100 \\
4 & 5 & 2.81 & 3.24 & 3.02 & 0.18 & 94.3 \\
5 & 6 & 2.70 & 3.07 & 2.88 & 0.32 & 90.0 \\
6 & 7 & 2.58 & 2.88 & 2.73 & 0.47 & 85.3 \\
\hline LSD $_{05}$ & & 0.17 & 0.25 & & & \\
\hline
\end{tabular}

Table 5 shows that the highest grain yield was obtained at a seeding depth of 4 and $5 \mathrm{~cm}$ (2.94 and $2.81 \mathrm{t} / \mathrm{ha}$ ), and the smallest one - at a depth of 2 and $7 \mathrm{~cm}$ (2.62 and $2.58 \mathrm{t} / \mathrm{ha}$ ). In 2020 experiments, when the seeding depth was 4 and $5 \mathrm{~cm}, 3.46-3.24$ t/ha were obtained; the lowest result was obtained in options 1 and 6 (2.93 and $2.88 \mathrm{t} / \mathrm{ha}$ ) die to the fact that the soil, with shallow seeding, dries out faster after precipitation, which moistened the top layer of the soil. With deep seeding $(7 \mathrm{~cm})$, the soil dried out to a great depth and the rains did not penetrate enough to the roots of spring wheat.

On average, over 2 years, the data obtained confirm that sowing is best at a depth of $4 \mathrm{~cm}$. This ensures better development of the aboveground part of plants, which increases the yield.

For the initial sample of factors, a second-order regression equation was obtained:

$$
\begin{gathered}
Y=103,312-0,582 * X_{2}+9,0702 * X_{1}+ \\
+0,0007 X_{2}^{2}+0,0018 * X_{1} X_{2}-1,1312 * X_{1}^{2} .
\end{gathered}
$$

where $\mathrm{Y}$ - yield; $\mathrm{X}_{1}-$ seeding depth; $\mathrm{X}_{2}-$ number of plants before harvesting.

Figue 1 shows the relationship between the yield, the number of plants before harvesting and the depth of seeding. The yield has a positive correlation with the number of plants before harvesting, and the relationship between the yield and the depth of seeding has a more complex structure. With a small and large depth of seeding, the yield is minimal due to the low moisture content in the upper soil layers and an insufficient amount of oxygen moisture in the lower layers.

Plants had the largest mass of 1000 seeds with a seeding depth of 4 and $5 \mathrm{~cm}-39.3$ and $38.7 \mathrm{~g}$. Higher germination energy - $90.4 \%$, laboratory germination rate of $95.2 \%$ and high grain uniformity of $92.6 \%$ were observed in option 3 with a seeding depth of $4 \mathrm{~cm}$.

Table 7 shows the data on the yield obtained in the 2020 experiments for Narmonka LLC, Laishevsk district and Timiryazev LLC, Baltasinsk district of the Republic of Tatarstan.

The seeding depth also has an ambiguous effect on the sowing quality of spring wheat grain (Table 6).

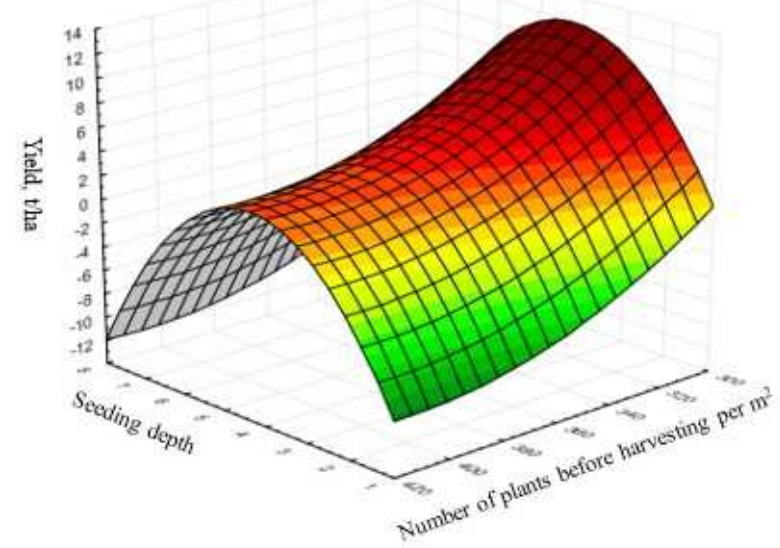

Fig. 1. Surface's graph

Table 6. Sowing quality of spring wheat grain depending on the depth of seeding (cf 2019-2020)

\begin{tabular}{|c|c|c|c|c|c|}
\hline Option & $\begin{array}{c}\text { Seeding } \\
\text { depth, cm }\end{array}$ & $\begin{array}{c}\text { Weight of } \\
\text { 1000 seeds, g }\end{array}$ & $\begin{array}{c}\text { Germination } \\
\text { energy, \% }\end{array}$ & $\begin{array}{c}\text { Laboratory } \\
\text { germination, \% }\end{array}$ & Evenness, \% \\
\hline 1 & 2 & 35.5 & 85.3 & 89.0 & 90.6 \\
2 & 3 & 37.7 & 88.6 & 91.7 & 91.9 \\
3 & 4 & 39.3 & 90.4 & 95.2 & 92.6 \\
4 & 5 & 38.7 & 90.0 & 94.6 & 91.3 \\
5 & 6 & 38.2 & 89.5 & 92.0 & 89.5 \\
6 & 7 & 35.0 & 85.1 & 88.7 & \\
\hline
\end{tabular}


Table 7. Ulyanovskaya 105g rain yield in production trials, t/ha (2020)

\begin{tabular}{|c|c|c|c|}
\hline Option & \multirow{2}{*}{$\begin{array}{c}\text { Seeding } \\
\text { depth, cm }\end{array}$} & \multicolumn{2}{|c|}{ Farms } \\
\cline { 3 - 4 } & & Narmonka LLC & $\begin{array}{c}\text { Timiryazev } \\
\text { LLC }\end{array}$ \\
\hline 1 & 2 & 2.63 & 2.48 \\
2 & 3 & 2.66 & 2.54 \\
3 & 4 & 2.75 & 2.63 \\
4 & 5 & 2.71 & 2.60 \\
5 & 6 & 2.61 & 2.50 \\
6 & 7 & 2.55 & 2.46 \\
\hline
\end{tabular}

Table 8. Economic efficiency of grain production of spring wheat variety Ulyanovskaya 105 (2019-2020)

\begin{tabular}{|c|c|c|c|c|c|c|c|}
\hline $\begin{array}{c}\text { *Experiment } \\
\text { options }\end{array}$ & $\begin{array}{c}\text { Seeding } \\
\text { depth, cm }\end{array}$ & $\begin{array}{c}\text { Productivity, } \\
\text { t / ha }\end{array}$ & $\begin{array}{c}\text { The cost of } \\
\text { production } \\
\text { from 1 } \\
\text { hectare, rub. }\end{array}$ & $\begin{array}{c}\text { Costs per } \\
\text { hectare, } \\
\text { rub. }\end{array}$ & $\begin{array}{c}\text { Net profit, } \\
\text { rub. }\end{array}$ & $\begin{array}{c}\text { Cost of 1 } \\
\text { ton of } \\
\text { grain, } \\
\text { rub. }\end{array}$ & $\begin{array}{c}\text { Profitability } \\
\text { level, \% }\end{array}$ \\
\hline 1 & 2 & 2,77 & 19390 & 12550 & 6840 & 4531 & 54,5 \\
2 & 3 & 2,97 & 20790 & 12870 & 7920 & 4333 & 61,5 \\
3 & 4 & 3,20 & 22400 & 13164 & 9236 & 4114 & 70,2 \\
4 & 5 & 3,02 & 21140 & 13465 & 7675 & 4208 & 56,9 \\
5 & 6 & 2,88 & 20160 & 13770 & 6390 & 4781 & 46,4 \\
6 & 7 & 2,73 & 19110 & 14090 & 5020 & 5161 & 35,6 \\
\hline
\end{tabular}

* Note: the purchase price of 1 ton of grain is 7000 rubles.

Improvement of individual elements of the technology of cultivation of spring wheat variety Ulyanovskaya 105 that increase its yield and sowing quality of seeds, is very beneficial in economic terms (Table 8).

The analysis of the efficiency of using different depths of planting seeds, as exemplified by the Ulyanovskaya 105 variety, shows that they largely determine the profitability of the production of this crop. In particular, the use of a seeding depth of $4 \mathrm{~cm}$ gives us reason to believe that the greatest profit from 1 hectare can be obtained with an optimal seeding depth (more than 9 thousand rubles).

Comparison of the level of profitability for the variants of the experiments shows that the 3rd variant of the experiment has the highest level of profitability $70.2 \%$. Calculations show that the smallest unit cost of the product obtained (4114 rubles per 1 ton) is observed in the third variant of the experiment, i.e. when seeding seeds to a depth of $4 \mathrm{~cm}$.

Similar indicators of the economic efficiency of grain production were noted in production experiments at OOO Narmonka and OOO Timiryazev.

The data indicate that in 2020 favorable meteorological conditions in Narmonka allowed the farm to obtain the highest yield at a seeding depth of 4 and $5 \mathrm{~cm}(2.75-2,7 \mathrm{t} / \mathrm{ha})$. When seeding at a depth of 2 and $7 \mathrm{~cm}$, the yield decreased to $2.63-2.55 \mathrm{t} / \mathrm{ha}$, i.e. by $4.4-6$ $\%$. Therefore, irrespective of the meteorological factors for the soil moisture supply, it is recommended to plant the seeds to a depth of $4-5 \mathrm{~cm}$. Similar data were obtained for Timiryazev LLC.

\section{Conclusion}

In the Predkamsk zone of the Republic of Tatarstan, on gray forest medium loamy soils, the seeds of spring wheat should be planted to a depth of $4-5 \mathrm{~cm}$. On average for 2 years, the highest yield was obtained at a seeding depth of 4 and $5-3.2$ and 3.02 t/ha. With a shallow seeding of $2 \mathrm{~cm}$ and a deeper seeding of $7 \mathrm{~cm}$, it decreased by $0.43-0.47 \mathrm{t} / \mathrm{ha}$ compared to the optimal option

\section{References}

1. M.F. Amirov, I.M. Serzhanov, F.Sh. Shaikhutdinov, M.Yu. Gilyazov, H.Z. Karimov, IOP Conf. Ser. Earth Envir. Sci., 341, 012025 (2019)

2. R. Sabirov, A. Valiev, L. Karimova, A. Dmitriev, D. Khaliullin, Engineering for Rural Development, pp. 555-562 (2019)

3. V.I. Kostin, F.A. Mudarisov, A.I. Krivova, Bull. of the Russian Academy of Natural Sciences, 6, 54-57 (2014).

4. R.I. Safin, L.Z. Karimova, F.N. Safiollin, Sh.Z. Validov, B.G. Ziganshin, K.Z. Karimov, G.S. Minnullin, E3S Web of Conf., 91, 185-193 (2019)

5. F.N. Safiollin, R.M. Nizamov, M.V. Panasyuk, S.R. Suleymanov, A.A. Akhmetzyanov, BIO Web of Conf., 17, 00241 (2020)

6. F.N. Safiollin, S.R. Suleymanov, S.V. Sochneva, N.V. Trofimov, I.G. Malganova, BIO Web of Conf., 17, 00062 (2020)

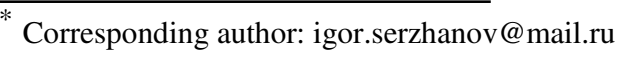


7. F.Sh. Shaikhutdinov, I.M. Serzhanov, M.F. Amirov, A.R. Valiev, R.M. Nizamov, IOP Conf. Ser. Earth and Envir. Sci., 341(1), 012091 (2019)

8. R. Minikayev, L. Gaffarova, BIO Web of Conf., 17 (2020)
9. A.M. Sabirzyanov, N.A. Loginov, I.P. Talanov, M.V. Panasyuk, T.G. Hadeyev, IOP Conf. Ser. Earth and Envir. Sci., 341 (2019)

10. M.Yu. Gilyazov, F.Sh. Faskhutdinov, R.V. Minikaev, Advances in Engineering Research, 151, 211-215 (2018) 